\title{
Rastreando o processamento de relativas de objeto: antecipação e integração de informação contextual na resolução de ambiguidades temporárias
}

\author{
Renê Forster ${ }^{a}$ \\ Letícia M. S. Corrêa ${ }^{b}$
}

\begin{abstract}
Resumo
Investiga-se o processamento incremental de orações relativas de objeto temporariamente ambíguas (relativas) completivas) em contextos favoráveis à integração de informação e antecipação do referente de um DP complexo. Busca-se verificar se informação contextual elimina a ambiguidade a favor de estruturas relativas, se informação de mais baixo nível (da interface sintaxe/prosódia) possibilita a distinção entre relativas e completivas a despeito do contexto, ou se, diante de ambiguidade estrutural, prevaleceria o princípio da aposição mínima, que favorece o processamento de completivas com consequente inibição da integração de informação. Um experimento com tarefa bimodal (apresentação oral de estímulos verbais e de estímulos visuais) de rastreamento ocular seguido de tarefa de compreensão, conduzido com falantes de português, é relatado. Os resultados são sugestivos da prevalência de princípios estruturais diante de ambiguidade temporária. Discutem-se as condições nas quais processos integrativos e antecipatórios podem ser conduzidos, por meio de um processador que opere em dois estágios.
\end{abstract}

Palavras-chave: Compreensão da linguagem; Ambiguidade; Relativas; Completivas; Rastreamento Ocular.

\footnotetext{
a Doutor em Estudos da Linguagem pela PUC-Rio, rene.forster@gmail.com

b Professora no Programa de Pós-Graduação em Estudos da Linguagem do Departamento de Letras da PUC-Rio, lesicor@gmail.com
} 


\section{Introdução}

Resultados obtidos por meio de diferentes técnicas experimentais (potenciais evocados: van BERKUM, HAGOORT e BROWN, 2000; HAGOORT e BERKUM, 2007; rastreamento ocular: TRUESWELL e TANENHAUS, 1992; ALTMANN e KAMIDE, 2007; LINDSAY et al., 2013; tempo de reação: MARSLEN-WILSON e TYLER, 1991) vêm sugerindo que informação de natureza não estrutural pode ser incrementalmente integrada durante a construção de representações sintáticas. Este trabalho integra esse campo de discussão investigando a emergência de processos integrativos e antecipatórios no curso do processamento de frases temporariamente ambíguas entre uma leitura relativa restritiva e uma leitura completiva, a partir da perspectiva do Modelo Integrado da Computação On-line (CORRÊA e AUGUSTO, 2006; 2007; AUGUSTO, CORREAA e FORSTER, 2012).

Orações relativas são estruturas encaixadas em um constituinte nominal (DP, determiner phrase). Caracterizamse por apresentarem um núcleo (head) nominal ao qual se encontra associada uma posição vazia (referida como gap $(\Delta)$ na literatura psicolinguística). No processamento sintático (parsing), a presença de um pronome relativo é indicativa dessa relação de dependência. $\mathrm{O}$ pronome sinaliza, portanto, que o nome que o precede (o núcleo da relativa) deve ser mantido ativo na memória de trabalho até que o gap seja encontrado. Uma vez encontrado o gap, a posição do elemento relativizado é identificada e seu papel temático pode ser atribuído (Corrêa, 1985; 1995). No caso de relativas de objeto (ORs) como (1), a relação de dependência sintática só se estabelece uma vez que a posição de argumento interno do verbo da relativa é encontrada vazia (ou com um pronome resumptivo). Em princípio, isso significa que, no curso da compreensão de uma relativa de objeto, o processador sintático só poderia ter a análise na relativa definida a partir do momento em que o verbo encaixado fosse encontrado.

(1) $\left[_{\mathrm{DP}}\right.$ A garota $\left[_{\mathrm{OR}}\right.$ que $\left[_{\mathrm{DP}}\right.$ o bombeiro] beijou $\left.\left.\Delta\right]\right]$ vai comprar um brinquedo 
No processamento incremental da sentença, no entanto, $\mathrm{o}$ referente do DP que contém uma relativa pode ser antecipado. Relativas restritivas supõem a existência de um set de referência no qual duas ou mais entidades podem ser diferenciadas por meio da informação trazidas por estas. Por exemplo, no caso de uma frase como (1), está implícita a existência de um set de referência no qual existe mais de uma garota, sendo que somente uma delas pode ser associada às informações trazidas pela relativa, ou seja, "o bombeiro beijou" apenas uma dentre as garotas do set. Forster et al. (2010) apresentaram evidência de que o mapeamento de um DP contendo uma oração relativa restritiva em um referente visualmente apresentado pode ser realizado já à altura do sujeito da relativa, quando este se constitui como informação distintiva (o bombeiro e não o palhaço, por exemplo, diante de eventos prévios em que um bombeiro havia beijado uma garota e um palhaço outra). Naquele estudo, verificou-se que a apresentação de um contexto prévio (por meio de informação visual e discursiva) pode prover meios para que o mapeamento do DP complexo a um referente seja antecipado ${ }^{1}$. Esses resultados são compatíveis com evidência sugestiva de que informação discursiva convergente pode reduzir o custo de processamento de sequências não ambíguas (GRODNER, GIBSON E WATSON, 2005) e de que informação de natureza visual possa ser rapidamente acessada e integrada (TANENHAUS et al., 1995; TRUESWELL et al., 1999).

A antecipação do referente de um DP complexo no processamento incremental de sentenças em contexto não necessariamente implica, contudo, que o contexto direcione a análise sintática do enunciado, como sugerido por teorias segundo as quais o processador é sujeito a restrições contextuais (eg. MACDONALD, PEARLMUTTER e SEIDENBERG, 1994). No contexto de um modelo integrado de computação on-line, que incorpora o conceito de fase (Chomsky, 1998), adaptado ao processamento incremental da esquerda para direita

1 Entende-se por mapeamento antecipado a busca por um referente para um DP no contexto visual mesmo antes que toda a informação linguística relevante para a individuação desse referente esteja disponível. (AUGUSTO, CORRÊA e FORSTER, 2012; CORRÊA et al. 2012; FORSTER, 2013), tomando-se o DP como "fase" (produto parcial da análise sintática transferido para os níveis de interface com sistemas de processamento), pode-se explicar a antecipação do referente de um DP contendo uma relativa a partir do 
reconhecimento do pronome relativo. Assim sendo, resultados como os de Foster et al. (2010) podem ser acomodados à ideia de um processador que analisa unidades sintáticas mínimas de forma modular.

Teorias em que o processador é sujeito a restrições de ordem contextual fariam prever, entretanto, que esse tipo de informação não apenas promove a antecipação do mapeamento do referente de um DP complexo como induz, incrementalmente, a análise sintática de uma oração contendo uma ambiguidade temporária. Diante da ambiguidade temporária entre uma oração relativa e uma completiva, promovida pelo complementizador/pronome relativo que em “...Maria contou ao amigo que ...", em contexto em que há mais de um amigo de Maria, um processador que atua com base em restrições contextuais anteciparia uma oração relativa (cf. van BERKUM, BROWN e HAGOORT, 1999; TRUESWELL e TANENHAUS, 1992). Um processador que privilegia informação sintática, em um primeiro momento, por outro lado, iniciaria a análise de uma completiva, regido pelo princípio da aposição mínima (que minimiza o custo computacional, ao vincular um segmento ambíguo ao nó mais alto da estrutura em análise) independentemente do contexto (FRAZIER, 1987). Informação proveniente da interface sintaxe-prosódia pode, não obstante, ter um papel importante na resolução de ambiguidades, sinalizando, em alguns casos, fronteiras para um processador sintático especializado (FODOR, 2002a, 2002b).

O modelo de computação on-line acima referido, por incorporar um processador autônomo, não prevê que o contexto discursivo possibilite a resolução imediata da ambiguidade estrutural. Este modelo é, não obstante, compatível com o direcionamento da análise com base em informação proveniente da interface sintaxe/prosódia, uma vez que informação de natureza prosódica pode contribuir para a delimitação de constituintes sintáticos (MORGAN, 1996).

O experimento aqui reportado buscou investigar, em que medida informação de baixo nível (estrutural ou da interface sintaxe/prosódia) se sobrepõe à informação contextual (de alto nível) favorável à antecipação de uma oração relativa restritiva, diante de contexto estruturalmente ambíguo. 


\section{Integração de informação e antecipação no curso processamento}

Um dos pressupostos de modelos de processamento sintático autônomo é o de que a primeira análise do parser não levaria em conta conhecimento de background. Um dos principais argumentos contra essa concepção tem advindo de pesquisas nas quais se aborda a influência de informação de natureza contextual durante a estruturação sintática. Defensores de modelos interativos argumentam que preferências de recência estrutural, que serviram de base para a atuação de princípios estruturais como o fechamento tardio (FRAZIER, 1979), poderiam ser revertidas por contextos diretivos (Cf. ALTMANN et al., 1998).

Nessa perspectiva, Berkum et al. (2003) apresentam resultados sugestivos de que a integração de informações discursivas pode acontecer em momentos iniciais do processamento. Períodos incoerentes com o contexto discursivo, como, por exemplo, "Jane told the brother that he was exceptionally slow", foram apresentados em um contexto no qual havia sido dito que o irmão de Jane teria sido rápido. Quando comparados com estímulos contendo violações semânticas no domínio da frase, o padrão elétrico detectado mostrou-se bastante similar, sendo caracterizado pela ocorrência de ondas N400 já num intervalo entre 150 e $200 \mathrm{~ms}$.

Também com base em potenciais evocados, constatou-se que informação contextual pode ser considerada em momentos iniciais do processamento de sequências potencialmente ambíguas - relativas ou completivas - em holandês (van BERKUM, BROWN e HAGOORT, 1999; Cf. van BERKUM, HAGOORT e BROWN, 2000; BRYSBAERT e MITCHELL, 2000). Nessa língua, dat (que) pode ser analisado como um pronome relativo ou complementizador. Contudo, este elemento só é ambíguo diante de nomes de gênero neutro. Diante de nomes de gênero comum, só pode ser complementizador. Sentenças como (4) e (5) foram apresentadas em contextos como (6) e (7). Aquele favoreceria uma leitura de completiva, enquanto este uma leitura de relativa. Foi detectado um padrão P600 quando (4) era apresentada após o contexto (7) na palavra desambiguizadora (em negrito), bem como no caso de (5) no 
contexto (6). O mesmo padrão foi mantido diante de nome de gênero comum (actrice $\left.{ }_{\mathrm{COM}}\right)$.

(4) David vertelde het meisje dat er visite kwam

David disse $a_{\mathrm{ART}}$ garota $_{\mathrm{NEU}}$ que $_{\mathrm{COMPL}}$ haveria alguns visitantes.

(5) David vertelde het meisje dat had zitten bellen op te hagen

David disse $\quad a_{\text {ART }} \quad$ garota $_{\mathrm{NEU}} \mathrm{que}_{\mathrm{RE}(\mathrm{NEU})}$ ficou no telefone para desligar.

(6) Contexto com 1 referente: Davi disse ao garoto e à garota para limparem seus quartos antes da hora do almoço. Mas o garoto ficou na cama toda a manhã e a garota ficou no telefone o tempo todo.

(7) Contexto com 2 referentes: Davi disse às garotas para limparem seus quantos antes da hora do almoço. Mas uma das garotas ficou na cama a manhã toda e a outra ficou no telefone o tempo todo.

Por outro lado, investigando os mecanismos de resolução de ambiguidades diante de informação contextual, também por meio da técnica de potenciais evocados, outro estudo apresentou contraevidências à hipótese de processamento em estágio único (VOS e FRIEDERICI, 2003). Indivíduos classificados de acordo com seu desempenho numa avaliação da memória de trabalho foram apresentados a relativas e completivas temporariamente ambíguas do alemão encabeçadas por um DP-objeto e antecedidas por informação contextual diretiva ou neutra. Nos indivíduos com maior capacidade de memória de trabalho, um padrão do tipo P600 foi detectado, à altura do elemento desambiguizador, em ambos os tipos de contexto apresentados (um indicativo de que estes indivíduos inicialmente interpretariam o DP inicial da sentença como sujeito, de acordo com a leitura preferencial deste tipo de estrutura, independentemente do contexto), enquanto, em indivíduos com baixa capacidade de memória, não houve emergência desse tipo de padrão (o que poderia estar associado a uma incapacidade de realizar a reanálise, pelas limitações da memória de trabalho). Contudo, resultados obtidos em perguntas de compreensão dos estímulos revelaram que os sujeitos com menor capacidade de memória registravam uma melhora em seu desempenho nas condições nas quais informação contextual diretiva era apresentada, sugerindo 
que se beneficiariam de informação discursiva apenas no processamento off-line.

No que diz respeito à ocorrência de processos antecipatórios, argumentou-se, em uma série de estudos (ALTMANN e KAMIDE, 1999; 2007; KAMIDE et al., 2003; KAMIDE, 2008), que movimentos oculares poderiam indicar, além de integração de informação discursiva, a antecipação de material linguístico não apresentado. Foi observado, por exemplo, que em uma sentença como "The boy will eat the cake", os participantes dirigiam seu olhar à ilustração de um bolo (em um set com outras ilustrações concorrentes) já a partir do segmento relacionado ao verbo da sequência de (ALTMANN e KAMIDE, 1999). Esse tipo de evidência tem sido interpretado, em geral, na perspectiva de processadores interativos. Contudo, há também evidência contrária à possibilidade de antecipação do mapeamento de referentes.

Em experimento com a técnica de rastreamento ocular, foram apresentadas frases como "Before making the dessert, the cook will crack/examine the egg that is in the bowl", contrastando a presença de verbos causativos e psicológicos na oração matriz (DI NARDO, 2005; 2011). Essas frases eram ouvidas concomitantemente a cenas dinâmicas, nas quais se apresentavam um possível Tema (eg., um pacote com ovos) e agente relacionados à ação denotada pelo verbo da oração principal. Nesses vídeos, o agente poderia se mover em direção ao objeto-Tema, se afastar dele ou permanecer em uma posição neutra. De acordo com os resultados, não foi verificado efeito da variável tipo de verbo, à exceção da condição na qual o agente movia-se em direção ao possível tema, o que significa que os participantes tenderam ao mesmo comportamento tanto diante de um verbo psicológico quanto diante de um verbo causativo (que poderia implicar em uma ação) nas duas outras condições. Além disso, não foram detectados indícios de antecipação, uma vez que, em média, as sacadas foram direcionadas ao objetoTema apenas depois do offset do DP crítico.

Os resultados apresentados nesta seção sugerem, por um lado, a integração incremental de informação contextual e a ocorrência de processos antecipatórios com base em informação não estrutural, evidência, em geral, considerada favorável à hipótese de um processador em estágio único. 
Também há, contudo, resultados sugerindo a atuação e preservação de princípios estruturais de análise, além da limitação da emergência de processos antecipatórios.

O experimento reportado a seguir teve por objetivo verificar em que medida processos integrativos e antecipatórios, tais como os evidenciados em Foster et al., 2010, se mantém no processamento de sentenças com ambiguidade temporária entre relativas e completivas. Os dois tipos de sentenças são apresentados com prosódia natural, em contexto que, tal como no estudo anterior, favorece a antecipação de uma relativa restritiva. Modelos em que o processador é restringido pelo contexto preveem efeitos de antecipação semelhantes aos anteriormente obtidos independentemente do tipo de estrutura apresentada. Modelos em que o processador sintático é autônomo, mas sensível à informação da interface sintaxeprosódia, preveem efeitos semelhantes apenas diante de orações relativas. Um modelo em dois estágios, não sensível à restrição prosódica, iria prever prevalência da aposição mínima, com mais erros de compreensão em orações relativas, devido à necessidade de reanálise.

\section{Experimento}

Os resultados reportados em Forster et al. (2010) sugerem que informação contextual (visual e verbal) pode ser integrada no processamento de um DP complexo contendo uma oração relativa restritiva, o que possibilita a antecipação de seu referente à altura do sujeito da relativa, quando o agente de um evento prévio, referente do sujeito da relativa, permite distinguir o objeto alvo.

O presente experimento visa a verificar em que medida informação dos níveis mais baixos de análise (estruturais e da interface sintaxe-prosódia) afeta a interpretação de um segmento temporariamente ambíguo (oração relativa ou completiva) em contexto que favorece a análise deste como oração relativa (contrariando o princípio estrutural de aposição mínima, que acarretaria a análise deste como completiva). Por exemplo, diante do segmento ambíguo em negrito em (8), a informação contextual em que há duas garotas e um pirata puxa uma delas pode favorecer a análise deste como relativa restritiva. 
O contorno prosódico esquematicamente delimitado em (8.1) é compatível com essa análise. No entanto, o contorno em 8.2 apresenta uma oração completiva, não havendo, portanto, em princípio possibilidade de sua integração com o contexto prévio.

Se o contexto determina a análise, a despeito dessa informação, então a busca pelo alvo de um DP complexo deve prevalecer, a despeito da estrutura e da prosódia. Se, ao contrário, o processador for sensível à prosódia, então a busca pelo referente do DP complexo fica restrita às relativas. Do contrário, apenas após o verbo ocorreria a desambiguização do segmento: em (8.1.), o objeto do verbo teria de ser preenchido pelo elemento relativizado (a garota), seguido do complemento do verbo da oração principal (falou duas mentiras). Em (8.2), o verbo da completiva subcategoria o objeto identificado.

Neste estudo, empregou-se uma técnica bimodal compreensão de sentenças apresentadas em áudio com rastreamento ocular da busca pelos referentes dos DPs em questão, seguida de tarefa de compreensão. Sentenças relativas e completivas temporariamente ambíguas são apresentadas em áudio, com prosódia normal (compatível com a estrutura), diante de contextos que favorecem a análise do segmento ambíguo como relativa restritiva, tal como em Forster et al (2010).

Um marujo disse pra garota que o pirata puxou...

(8.1) Um marujo disse pra garota que o pirata puxou duas mentiras. (relativa)

(8.2) Um marujo disse pra garota que o pirata puxou quatro barris. (completiva)

Como naquele estudo, dois elementos poderiam permitir a antecipação do referente, no caso de o segmento ambíguo ser processado como relativa: o DP agente e o verbo. Dois tipos de contexto prévio foram então criados. Para metade dos estímulos, duas ações semelhantes sobre dois objetos de um mesmo tipo, executadas por dois agentes diferentes (Contexto A). Por exemplo: um pirata puxa uma garota e um palhaço puxa outra garota. Nesse caso, diante de 8.1. é possível antecipar o referente do DP complexo assim que o DP sujeito (o pirata) é processado e interpretado como agente. Na outra metade dos estímulos, ações diferentes são executadas por um mesmo tipo 
de agente sobre diferentes garotas (Contexto B). Por exemplo: um pirata puxa uma garota e o outro pirata beija outra garota. Assim, somente diante do verbo seria possível antecipar o referente do DP complexo, no caso de o segmento ambíguo ser processado como relativa. Os elementos críticos para integração da informação prévia com o segmento em análise são o sujeito e o objeto da sentença ambígua, nos contextos A e $B$, respectivamente.

Têm-se assim duas variáveis independentes: Contexto $(\mathrm{A}$ : elemento crítico $=\mathrm{DP}$ agente; $\mathrm{B}$ : elemento crítico $=$ verbo $)$ e tipo de estrutura (relativa / completiva), sendo a primeira um fator grupal. $\mathrm{O}$ cruzamento dessas variáveis resultou em quatro condições (Tabela 1). Na análise do comportamento ocular, a variável dependente foi o número de rodadas (trials) com fixação no referente alvo do que pode ser processado como um DP complexo. As fixações foram medidas em dois pontos: P1 (durante a emissão do DP sujeito do segmento ambíguo) e P2 (durante a emissão do verbo deste segmento). Após a audição do estímulo, seguiu-se uma tarefa de compreensão (tarefa offline): uma pergunta referente ao objeto do verbo da oração principal. A variável dependente nesta tarefa foi o número de respostas corretas. Diante de 8.1, a resposta correta seria "duas mentiras". Em 8.2, a resposta correta seria "que o pirata puxou quatro barris".

Tabela 1 - Condições experimentais

\begin{tabular}{lcc}
\hline & \multicolumn{2}{c}{ Variável independente } \\
& Contexto & Tipo de estrutura \\
\hline Condição 1 $(C 1)$ & $A$ & relativa \\
Condição 2 $(C 2)$ & $A$ & completiva \\
Condição $3(C 3)$ & $B$ & relativa \\
Condição $4(C 4)$ & $B$ & completiva \\
\hline
\end{tabular}

Contexto A: elemento crítico = DP agente;

Contexto B: elemento crítico $=$ verbo

A partir das variáveis apresentadas, foram feitas as seguintes previsões. (i) Se a informação contextual predominar, é previsto um efeito principal de Contexto nos pontos P1 e 
P2. Em P1, maior número de rodadas (trials) com fixações no alvo, no contexto A do que no contexto B é esperado; (ii) Se a informação proveniente da interface sintaxe-prosódia predominar, um efeito principal de tipo de sentença é esperado com maior número de fixações no alvo na relativa do que na completiva em P1 e em P2.

A hipótese nula é que não há integração ou antecipação de referentes, diante da preferência do processador pela aposição mínima, que resulta na análise de completivas, o que deverá acarretar, na tarefa off-line, maior número de acertos nas completivas, dada a necessidade de reanálise das relativas.

\subsection{Método}

\subsubsection{Participantes}

Participaram deste experimento 47 voluntários da comunidade da Universidade Estadual da Zona Oeste (UEZO). O grupo era composto por 28 homens e 19 mulheres, com média de idade de 23 anos. Do total de participantes, 11 foram descartados da amostra, por erros do experimentador, por problemas técnicos em geral ou por falhas no rastreamento. Estes foram divididos em 2 grupos em função da variável contexto: um grupo foi apresentado visual e verbalmente a dois eventos prévios com diferentes agentes executando uma mesma ação (compatível com o DP sujeito do segmento ambíguo como elemento crítico para integração de informação) (Contexto A); outro grupo foi apresentado a dois eventos prévios com um mesmo agente executando duas ações diferentes (compatível como verbo como elemento crítico para integração de informação) (Contexto B).

\subsubsection{Material}

Foram criadas 16 sentenças experimentais, sendo 8 contendo uma relativa de objeto ramificada à direita e 8 sentenças completivas em seguida ao objeto indireto. A ambiguidade temporária é eliminada no DP que segue o segundo verbo da sequência: complemento do verbo da oração principal (no caso relativas) e complemento do verbo da oração 
completiva. As sentenças experimentais foram distribuídas em duas listas distintas, de forma que sentenças relativas e completivas semelhantes não fossem apresentadas a um mesmo participante. Os estímulos auditivos foram gravados em prosódia natural ${ }^{2}$. Foram construídos também 24 estímulos distratores que poderiam ter a estrutura de uma passiva ou de uma declarativa, nenhuma delas contendo orações completivas ou relativas. A figura 1 ilustra os estímulos críticos apresentados visualmente e em áudio.

Figura 1 - Sequência de estímulos experimentais

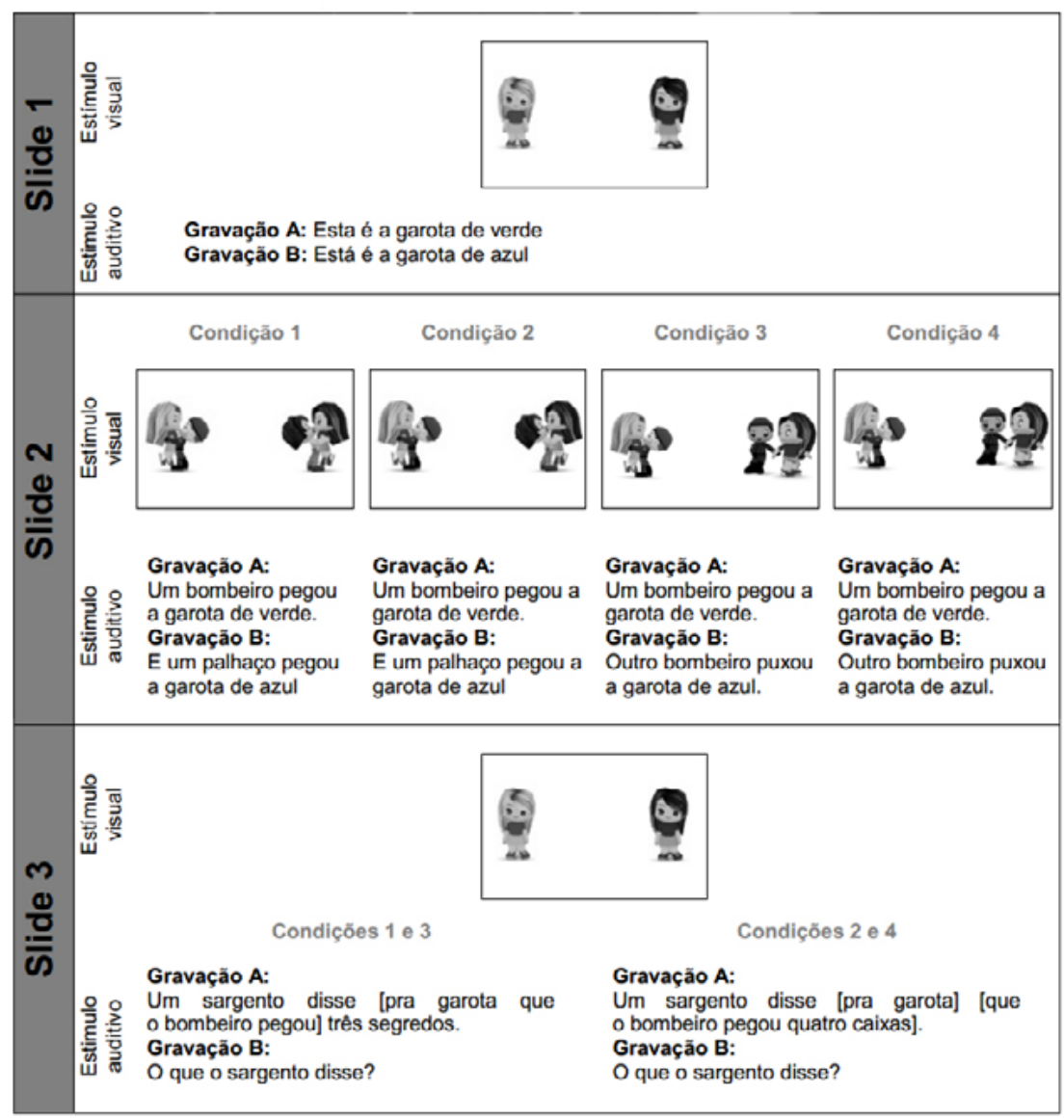

No que diz respeito aos estímulos visuais, ao todo, foram criados 105 slides para este experimento, sendo 7 deles utilizados na etapa de pré-teste, 32 nas rodadas experimentais e os demais nos distratores. Cada rodada (trial) do experimento 
compreendia a apresentação de três slides (Figura 1). Cada um dos slides acrescido dos áudios que lhes correspondiam foi convertido em arquivo de vídeo, gerando um total de 98 arquivos ( $\mathrm{O}$ anexo 1 apresenta as sentenças utilizadas).

\subsubsection{Aparato}

Foi utilizado um computador portátil Apple com sistema operacional Windows e com o software Tobii Studio, responsável pela calibração, apresentação dos estímulos, coleta e análise parcial dos dados. O eye-tracker utilizado foi um Tobii TX120.

\subsubsection{Procedimento}

Os voluntários foram informados de que participariam de uma tarefa de compreensão na qual deveriam ouvir sentenças, à medida que viam a projeção de slides, na tela de um computador, e responder a uma pergunta. A calibração do equipamento era realizada no início e repetida no meio de cada sessão. Cada rodada (trial) experimental consistia da apresentação de três slides. No terceiro deles, era apresentada a sentença experimental e, cerca de 3 segundos depois, uma interrogativa QU-. A duração média de uma sessão era de 40 minutos.

\subsubsection{Análise das medidas}

Em primeiro lugar, cada um dos arquivos de vídeo foi analisado, com auxílio de um oscilograma, com vistas a estabelecer os marcos de tempo que delimitavam o início e o fim de cada ponto considerado para análise (P1 e P2). A movimentação ocular dos participantes foi registrada pelo Tobii Studio. Nesse programa, definiam-se as áreas de interesse correspondentes a cada um dos estímulos experimentais, delimitadas pela borda externa de cada um dos personagens apresentados no slide 3 . Considerando tais áreas, o programa gerava planilhas de dados relativos à movimentação ocular de cada participante, nas quais eram listadas as ocorrências de fixações nas áreas de interesse a cada amostra/frame. Nestas planilhas, selecionavam-se, 
manualmente, os dados relativos aos conjuntos de frames correspondentes a cada um dos segmentos de análise. A partir dessa seleção, eram contabilizadas as rodadas (trials) nas quais foram registradas fixações no alvo do que seria o DP complexo, na análise de relativas.

\subsection{Resultados}

Os dados foram submetidos a duas ANOVAs (2x2), uma para cada ponto (P1 e P2). Em P1 não houve efeitos principais, nem interação significativos (Contexto: $\mathrm{F}(1,34)=2,97, \mathrm{p}=10$; Tipo de estrutura $\mathrm{F}(1,34)=2,40$, p.13); Contexto e Tipo de estrutura $(\mathrm{F}(1,34)=2,97, \mathrm{p}=.89)$. Assim, nesse ponto (Gráfico 1), não houve indicativo de que informação de natureza contextual pudesse induzir uma análise relativa, gerando o mapeamento antecipado do referente da relativa nas condições 1 e 2 ou de que informação proveniente da interface sintaxe-prosódia fosse considerada na análise inicial da ambiguidade. Também não houve efeitos significativos no ponto 2 (Contexto; $\mathrm{F}(1,34)=2,39$, $\mathrm{p}=.13$; Tipo de estrutura $\mathrm{F}(1,34)=0,014, \mathrm{p}=.91)$; Contexto e Tipo de Estrutura $F(1,34)=2,39, p=.13)$.

Gráfico 1 - Médias de rodadas (trials) com fixação no alvo em função de contexto e tipo de estrutura no ponto 1 (escore máximo: 4)

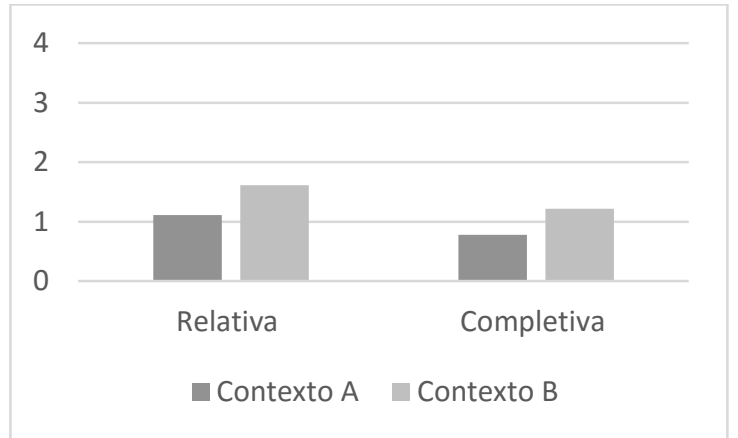

Gráfico 2 - Médias de rodadas (trial) com fixação no alvo em função de contexto e tipo de estrutura no ponto 2 (escore máximo: 4)

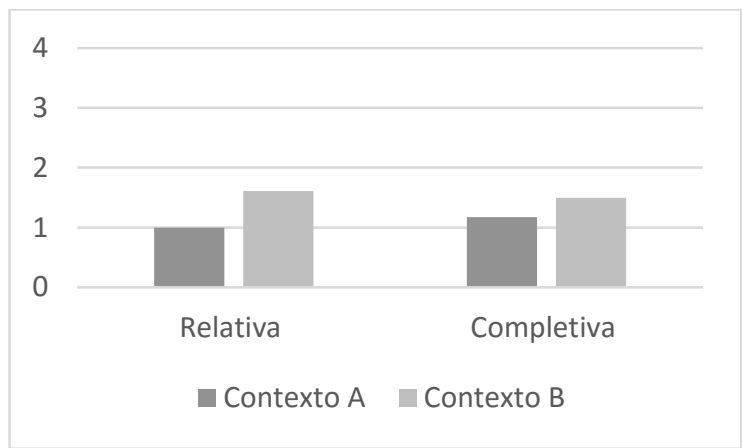


Como se observa, os resultados, de um modo geral, demonstram um baixo número de rodadas (trials) com fixação no referente alvo do DP complexo, no caso de o segmento ambíguo ser analisado como relativa. Além disso, não foram encontradas diferenças significativas entre as condições contrastadas. Diante disso, foi considerada a possibilidade de a ausência de resultados significativos se dever a um efeito de spillover acarretado pelo tempo necessário à programação da sacada (MATIN, SHAO e BOFF, 1983; Cf. FINDLAY e WALKER, 2011). Dessa forma, foram realizadas duas novas ANOVAs (2x2), tomando-se uma distinta segmentação dos estímulos, na qual os pontos 1 e 2 foram deslocados $200 \mathrm{~ms}$ adiante. Também não foram obtidos efeitos significativos.

Em P1 (Gráfico 3), considerando a compensação do tempo relativo à programação da sacada, embora, novamente, tenha havido uma pequena vantagem das relativas em relação às completivas, não foram encontrados efeitos ou diferenças significativos (Contexto: $\mathrm{F}(1,34)=2,62, \mathrm{p}<.11$; Tipo de estrutura: $\mathrm{F}(1,34)=0,75, \mathrm{p}<.39$; Interação: $\mathrm{F}(1,34)=0,015, \mathrm{p}<.90)$.

Em P2 (Gráfico 4), nessa nova análise, também não foram obtidos efeitos nas comparações entre as variáveis (Contexto: $\mathrm{F}(1,34)=0,96, \mathrm{p}<.34$; Tipo de estrutura: $\mathrm{F}(1,34)=2,19$, $\mathrm{p}<.15$; Interação: $\mathrm{F}(1,34)=0,97, \mathrm{p}<.33)$. As comparações pareadas, contudo, revelaram uma tendência de mais rodadas (trials) com fixações na condição 3 quando comparada à condição $4(t(17)=1,82 ; p<.09)$. Este resultado poderia indicar que a informação verbal distintiva nesse segmento poderia ter permitido o mapeamento da sentença relativa em um referente, embora esse resultado não possa ser considerado conclusivo, uma vez que o deslocamento do segmento 2 para $200 \mathrm{~ms}$ adiante permite que parte do material relativo ao DP final, que desambiguiza a sentença, seja englobado nesse segmento. 
Gráfico 3 - Médias de rodadas (trials) com fixação no alvo em função de contexto e tipo de estrutura no ponto 1 (escore máximo: 4)

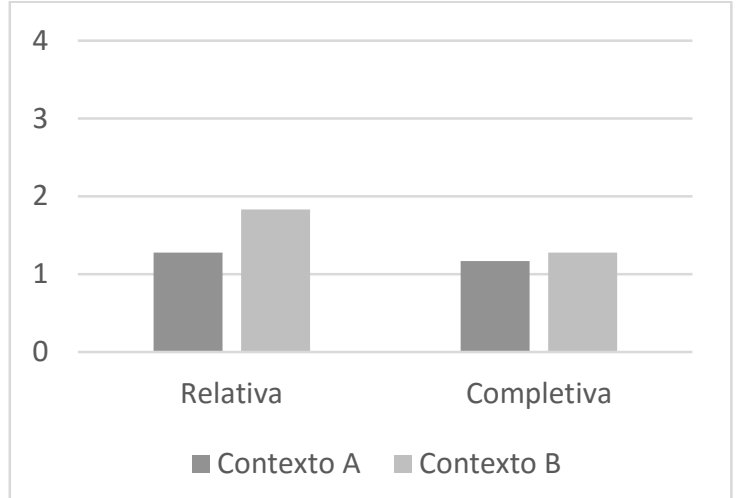

Gráfico 4 - Médias de rodadas (trial) com fixação no alvo em função de contexto e tipo de estrutura no ponto 2 (escore máximo: 4)

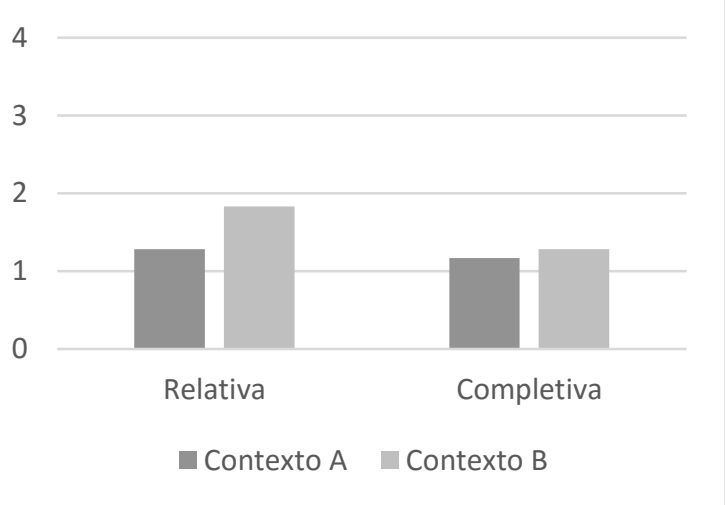

Os resultados obtidos não permitem, portanto, que se rejeite a hipótese nula, qual seja, a de que, diante de um segmento ambíguo, o processador adota o que seria o procedimento default de acordo com o princípio da aposição mínima. Consequentemente, o segmento ambíguo é analisado como oração completiva, a despeito do contexto prévio e da prosódia compatível com o tipo de estrutura em questão. Esse resultado permite prever um maior número de respostas corretas nas orações completivas do que nas orações relativas, na tarefa off-line, dado que a ambiguidade seria percebida diante do complemento do verbo, acarretando a necessidade de reanálise das relativas. O resultado de um teste-t sustenta essa previsão $(\mathrm{t}(35)=6,52 \mathrm{p}<.0001)$. O gráfico 5 apresenta as médias em função do tipo de estrutura.

Tem-se que $90,5 \%$ das respostas incorretas na tarefa off-line foram obtidas diante em estímulos que continham orações relativas. Assim, por exemplo, diante de um estímulo experimental como em (9), alguns participantes forneciam respostas como "que o goleiro beijou duas fofocas", sem mesmo notarem a necessidade de reanálise, diante da anomalia semântica criada. Como se observa, os participantes ignoraram a coerência semântica da sentença, preservando uma possível análise inicial, na qual a ambiguidade temporária das relativas conduziria a uma leitura completiva. 
Gráfico 5 - Número de respostas corretas na tarefa off-line em função do tipo de estrutura (escore máximo $=4$ )

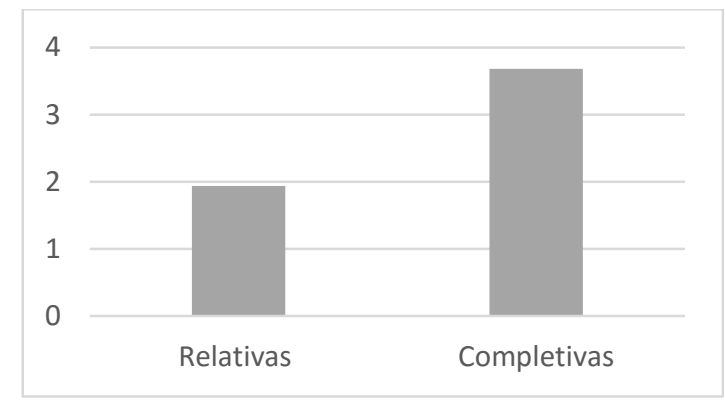

(9) Um técnico falou [pro garoto que o goleio beijou] [duas fofocas]. O que o técnico falou?

\section{Discussão}

Os resultados obtidos demonstraram que, diante de um segmento temporariamente ambíguo (entre relativas e completivas), os efeitos de integração de informação e antecipação do referente do DP complexo obtidos em sentenças sem ambiguidade estrutural não se mantém. Prevalece o princípio da aposição mínima independentemente do tipo de estrutura. Os presentes resultados não proveem suporte, portanto, nem para modelos em um estágio, segundo os quais o processador sintático é sensível a restrições contextuais, nem a modelos nos quais o processador leva em conta informação proveniente da interface sintaxe-prosódia. O modelo de computação on-line a partir do qual os resultados em Foster et al. (2010) e Forster (2013) foram explicados permite dar conta dos presentes resultados, dado que supõe um processador autônomo. Por outro lado, tal modelo é compatível com um possível direcionamento da análise, proveniente da interface sintaxe-prosódia, que atuaria na delimitação dos chunks a serem incrementalmente analisados, semanticamente interpretados e integrados ao contexto de enunciação.

A ausência de um efeito de estrutura, diante de informação prosódica compatível, pode decorrer do baixo engajamento dos participantes na compreensão dos estímulos, como sugerem as respostas em que a anomalia semântica não é tomada como indicativa da necessidade de reanálise. Tal baixo engajamento 
pode ser devido ao número de estímulos, ao fato de o contexto prévio ser desprezível em metade dos estímulos (completivas) e em parte dos distratores, o que pode acarretar a estratégia de não o levar em conta durante a tarefa, diferentemente de em Foster et al. (2010), em que apenas relativas restritivas foram apresentadas.

Assim sendo, para que se avalie um possível efeito de estrutura decorrente da interface sintaxe/prosódia compatível com o modelo de computação on-line cujo processador autônomo opera por unidades (equivalentes a fases), uma alteração na metodologia de testagem se impõe. O contraste entre estruturas ambíguas com e sem informação prosódica, em tarefa em que a integração de informação se mostre relevante, pode vir a clarificar esse ponto.

\section{Conclusão}

Contrariando a previsão de modelos baseados em restrições contextuais, assim como a previsão da sensibilidade de um processador incremental à informação proveniente da interface sintaxe-prosódia, o experimento aqui relatado sugere que, diante de ambiguidade estrutural (relativa-completiva), prevalece o princípio da aposição mínima, o que inibe qualquer tipo de integração de informação contextual e antecipação do referente do DP complexo de uma relativa. A possibilidade de processos integrativos e antecipatórios serem implementados parece, pois, ser limitada a estruturas não ambíguas em situações que levem ao engajamento do participante à integração de informação, como em Forster et al. (2010). Forster (2013) argumenta a favor de um processador autônomo para dar conta dos processos integrativos e antecipatórios obtidos no processamento de relativas restritivas. Ainda que esse processador dê conta da prevalência da aposição mínima nos presentes resultados, permanece a questão do quanto de engajamento do participante na integração de informação ao contexto de enunciação é necessário para que processos integrativos se manifestem em segmentos ambíguos. Uma vez garantido esse engajamento, será possível avaliar em que medida ambiguidade estrutural restringe esses efeitos a despeito de informação de baixo nível (da interface sintaxe-prosódia) poder, em princípio, eliminar a ambiguidade em questão. 
Em suma, o presente estudo abre um caminho para maior refinamento das condições linguísticas e metodológicas necessárias para que a integração incremental de informação seja investigada.

\section{REFERÊNCIAS}

ALTMANN, G.; KAMIDE, Y. Incremental interpretation at verbs: restricting the domain of subsequent reference. Cognition, v. 73, p. 247-264, 1999.

ALTMANN, G.; KAMIDE, Y. The real-time mediation of visual attention by language and world knowledge: Linking anticipatory (and other) eye movements to linguistic processing. Journal of Memory and Language, v. 57, p. 502-518, 2007.

ALTMANN, G. T. M.; VAN NICE, K. Y.; GARNHAM, A.; HENSTRA, J. Late closure in context. Journal of Memory and Language, v. 38, p. $459-484,1998$.

AUGUSTO, M. R. A.; CORRÊA, L. M. S.; FORSTER, R. An argument for DPs as phases in an integrated model of on-line computation: the immediate mapping of complex DPs with relative clauses. Revista Virtual de Estudos da Linguagem - ReVEL, v. 10, n. 06, 7-26, 2012.

BRYSBAERT, Marc; MITCHELL, Don C. The failure to use gender information in parsing: A comment on van Berkum, Brown, and Hagoort (1999). Journal of Psycholinguistic Research, v. 29, n. 5, p. 453-466, 2000.

CHOMSKY, N. On phases. Mass: MIT Press. 2005.

CORREAA, L. M. S.; AUGUSTO, M. R. A. Computação linguística no processamento on-line: em que medida uma derivação minimalista pode ser incorporada em modelos de processamento? In: ENCONTRO NACIONAL DA ANPOLL, 21, 2006. Texto para discussão na sessão Inter-GTs (Psicolinguística e Teoria de Gramática), 2006.

CORREAA, L. M. S.; AUGUSTO, M. R. A. Computação linguística no processamento on-line: soluções formais para a incorporação de uma derivação minimalista em modelos de processamento. Cadernos de Estudos Linguísticos, v. 49, p. 167-183, 2007. 
CORREAA, L. M. S.; AUGUSTO, M. R. A.; LONGCHAMPS, J.; FORSTER, R. Referência Anafórica com relativas restritivas de objeto: custo relativizado na interface gramática-pragmática. Revista Linguistica, v. 8, n. 2, 2012.

Di NARDO, J. Eye movements as a function of spoken sentence comprehension and scene perception. Dissertação (Master of Arts - Psychology) - Concordia University, Montreal, Quebec, Canadá, 2005.

Di NARDO, J. Building event meanings from linguistic and visual representations: evidence from eye movements. Tese (Doutorado em Psicologia) - Departament of Psychology, Concordia University, Montreal, Quebec, Canadá, 2011.

FERRETTI, T. R.; MCRAE, K.; HATHERELL, A. Integrating verbs, situation schemas and thematic role concepts. Journal of Memory and Language, v. 44, p. 516-547, 2011.

FINDLAY, J.; WALKER, R. Human saccadic eye movements. Scholarpedia. 2011. Disponível em: <http://www.scholarpedia. org/w/index.php?title=Human_saccadic_eye_movements\&a ction=cite\&rev=122018. Acesso em: set. 2012.

FINGER, I.; ZIMMER, M. A preferência da interpretação de orações relativas curtas e largas en Português Brasileiro. Processamento da linguagem, p. 111-130, 2005.

FODOR, J. D. Prosodic disambiguation in silent reading. In: HIROTANI, M. (Ed.). Proceedings of the North East Linguistic Society 32. Amherst: University of Massachusetts, 2002a.

Psycholinguistics cannot escape prosody. In: SPEECH PROSODY CONFERENCE, 2002, Aix-en-Provence, França. Proceedings... 2002b.

FORSTER, R.; CORREA, L. M. S.; AUGUSTO, M. R. A.; RODRIGUES, E. S. Integrating information: the incremental processing of restrictive object relative clauses in Brazilian Portuguese. In: FRANÇA, A. I.; MAIA, M. (org.). Papers in Psycholinguistics: Proceedings of the First International Psycholinguistics Congress. Rio de Janeiro : Imprinta, 2010.

FORSTER, Renê. Aspectos do processamento de orações relativas: antecipação de referentes e integração de informação contextual. 2013. Tese - Pontifícia Universidade Católica do Rio de Janeiro. Orientadora: Letícia Maria Sicuro Corrêa. 
FRAZIER, L. On comprehending sentences: Syntactic parsing strategies. ETD Collection for University of Connecticut, 1979.

Sentence Processing: A tutorial review. In: COLTHEART, M. (Ed.). Attention and performance XII: The psychology of reading. Hillsdale, NJ: Lawrence Erlbaum Associates, 1987, p. 559-586.

GRODNER, D.; GIBSON, E.; WATSON, D. The influence of contextual contrast on syntactic processing: Evidence for strong-interaction in sentence comprehension. Cognition, v. 95, p. 275-296, 2005.

HAGOORT, P.; Van BERKUM, J. Beyond the sentence given. Phil. Trans. R. Soc, v. 362, p. 801-811, 2007.

KAMIDE, Y. Anticipatory processes in sentence processing. Language and Linguistics Compass, v. 2, n. 4, p. 647-670, 2008.

KAMIDE, Y.; ALTMANN, G.; HAYWOOD, S. L. The timecourse of prediction in incremental sentence processing: Evidence from anticipatory eye-movements. Journal of Memory and Language, v. 49, p. 133-59, 2003.

LINDSAY, Shane; SCHEEPERS, Christoph; KAMIDE, Yuki. To Dash or to Dawdle: Verb-Associated Speed of Motion Influences Eye Movements during Spoken Sentence Comprehension. PLOS ONE, v. 8, n. 6, p. e67187, 2013.

LOURENÇO-GOMES, M. C. Efeito de comprimento do constituinte na interpretação final de orações relativas estruturalmente ambíguas: um estudo baseado na Hipótese da Prosódia Implícita. 2003. Dissertação (Mestrado em Linguística) - Faculdade de Letras, Universidade Federal do Rio de Janeiro (UFRJ), 2003.

MACDONALD; PEARLMUTTER; SEIDENBERG. Lexical Nature of Syntactic ambiguity resolution. Psychological Review, v. 10, p. 676-703, 1994.

MARSLEN-WILSON, W;; TYLER, L. K. Againist Modularity. In: GARFIELD, J. L. (Ed.). Modularity in Knowledge Representation and Natural-Language. The MIT Press, 1991.

MATIN, E.; SHAO, K.; BOFF, K. Saccadic overhead: information processing time with and without saccades. Perception $\mathcal{E}$ Psychophysics, v. 53, p. 372-380. 1993. 
MORGAN, James L. Prosody and the roots of parsing. Language and cognitive processes, v. 11, n. 1-2, p. 69-106, 1996.

TANENHAUS, M. K.;SPIVEY-KNOWLTON, M. J.;EBERHARD, K. M.; SEDIVY, J. E. Integration of visual and linguistic information in spoken language comprehension. Science, v. 268, p. 1632-1634, 1995.

TRUESWELL, J. C.; SEKERINA, I.; HILL, N. M.; LOGRIP, M. $\mathrm{L}$. The kindergarten-path effect: studying on-line sentence processing in young children. Cognition, v. 73, p. 89-134, 1999. TRUESWELL, J. C.; TANENHAUS M. K. Consulting temporal context during sentence comprehension: evidence from the monitoring of eye movements in reading. In: ANNU. CONF. COGN. SCI. SOC., 1992. Abstracts... 1992.

VAN BERKUM, J. J.; BROWN, C. M.; HAGOORT, P. Early referential context effects in sentence processing: Evidence from event-related brain potentials. Journal of Memory and Language, v. 41, p. 147-182, 1999.

VAN BERKUM; HAAGOORT; BROWN. The use of referential context and grammatical gender in parsing: a reply to Brysbaert and Mitchell (2000). Journal of Psycholinguistic Research, v. 29, n. 5, 2000.

VAN BERKUM, J. J.; ZWITSERLOOD, P.; HAGOORT, P.; BROWN, C. M. When and how do listeners relate a sentence. to the wider discourse? Evidence from the N400 effect. Cognitive Brain Research, v. 17, p. 701-718, 2003.

VOS, S. H.; FRIEDERICI, A. D. Intersentential syntactic context effects on comprehension: The role of working memory. Cognitive Brain Research, v. 16, n. 1, p. 111-122, 2003. 


\section{Anexo 1}

(1) Um marujo falou [pra garota que o pirata puxou][duas mentiras].

(2) Um sargento disse [pra garota que o bombeiro pegou][três segredos].

(3) Um técnico falou [pro garoto que o goleiro beijou][duas fofocas].

(4) Um servente disse [pro garoto que o pedreiro pulou][três segredos].

(5) Um aluno disse [pra garota que o professor pulou][três segredos].

(6) Um feirante falou [pra garota que o padeiro beijou][duas fofocas].

(7) Um músico disse [pro garoto que o palhaço pegou][três segredos].

(8) Um médico falou [pro garoto que o cacique puxou][duas mentiras].

(9) Um marujo falou [pra garota][que o pirata puxou quatro barris].

(10) Um sargento disse [pra garota][que o bombeiro pegou quatro caixas].

(11) Um técnico falou [pro garoto][que o goleiro beijou duas meninas].

(12) Um servente disse [pro garoto][que o pedreiro pulou três barreiras].

(13) Um aluno disse [pra garota][que o professor pulou três barreiras].

(14) Um feirante falou [pra garota][que o padeiro beijou duas meninas].

(15) Um músico disse [pro garoto][que o palhaço pegou quatro caixas].

(16) Um médico falou [pro garoto][que o cacique puxou quatro barris]. 


\section{Abstract \\ (Eye)-tracking object relative clauses processing: anticipation and integration of contextual information on amibiguity resolution}

The on-line processing of temporarily ambiguous object relative clauses (relative clause/complement clause) is investigated in contexts that favor the incremental integration of information and the anticipation of the referent of a complex DP. The research questions are: Does contextual information eliminate ambiguity in favor of relative clauses? Does low level information (from the syntax/prosody interface) enable relative and complement clauses to be distinguished? Or does minimal attachment prevail in the presence of structural ambiguity thereby inhibiting the incremental integration of information? An experiment is reported in which a bimodal task (verbal (oral) and visual stimulus presentation) with eye-tracking is carried out, followed by a comprehension task. The participants were adult speakers of Portuguese. The results suggest that structural principles prevail when there is temporary ambiguity. The conditions are discussed in which integrative and anticipatory processes can be conducted by means of two-stage processor.

Key words: Language Comprehension; Ambiguity; Relative Clauses; Complement Clauses; Eye-tracking. 